\title{
Osteomalacia and Fanconi Syndrome Induced by Adefovir
}

\author{
Natsumi Matsuoka ${ }^{1,2}$, Haruhito A. Uchida ${ }^{1,3}$, Yoshikazu Hara ${ }^{2}$ and Hiroto Matsuda ${ }^{2}$
}

Key words: osteomalacia, Fanconi syndrome, adefovir, chronic hepatitis B

(Intern Med 58: 1659, 2019)

(DOI: 10.2169/internalmedicine.2229-18)

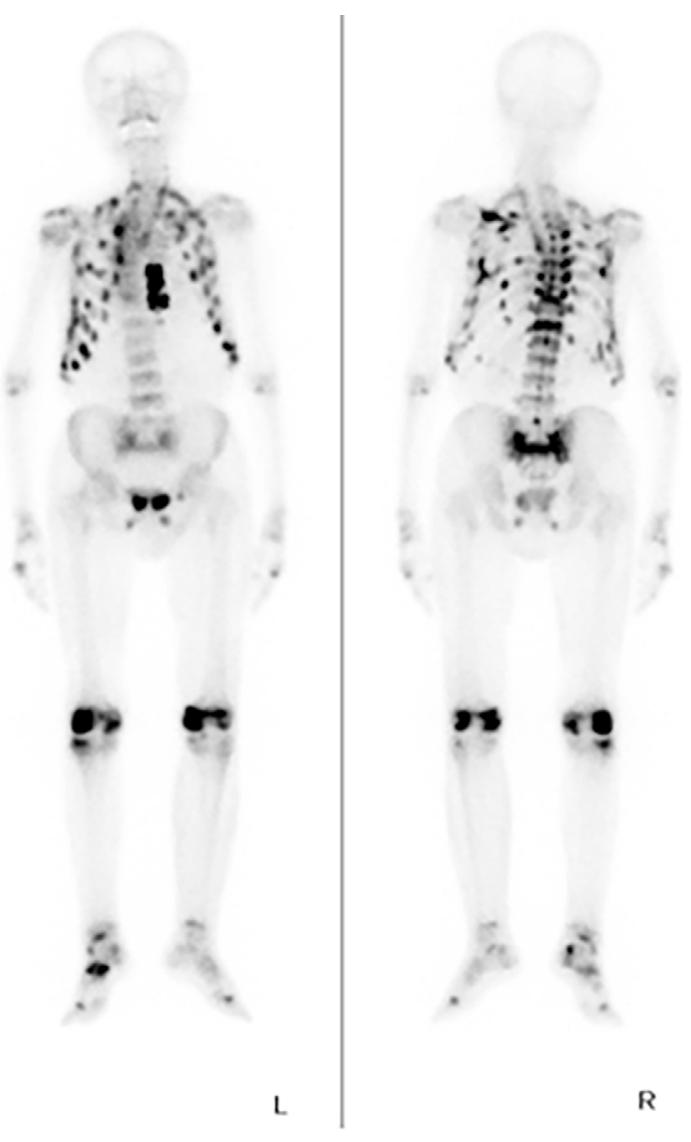

Picture.
A 77-year-old man with a history of taking adefovir at 10 $\mathrm{mg} /$ day for 10 years for chronic hepatitis B was referred due to multiple fractures without any trauma. He had mild renal dysfunction ( $\mathrm{sCr} 1.28 \mathrm{mg} / \mathrm{dL}$ ), hypophosphatemia (iP 1.9 $\mathrm{mg} / \mathrm{dL}$ ), hypouricemia (UA $1.4 \mathrm{mg} / \mathrm{dL}$ ), phosphaturia, glycosuria without hyperglycemia, non-anion-gap metabolic acidosis, a normal range of vitamin $\mathrm{D}$ and intact parathormone, and a high concentration of ALP (922 IU/L), indicating a diagnosis of Fanconi syndrome. A renal biopsy revealed interstitial nephritis and intact glomeruli, compatible with the diagnosis. Bone scintigraphy showed an uptake at multiple points, including the costochondral junction, sternum and pseudofractures, demonstrating osteomalacia caused by Fanconi syndrome (Picture). After switching from adefovir to entecavir and starting alfacalcidol and phosphates, the patient's incident pain and laboratory findings dramatically improved. Regular monitoring of the renal function, including serum uric acid, serum phosphate, and urinalysis findings, is recommended to avoid Fanconi syndrome associated with the prolonged use of adefovir (1).

The authors state that they have no Conflict of Interest (COI).

\section{Reference}

1. Eguchi H, Tsuruta M, Tani J, et al. Hypophosphatemic osteomalacia due to drug-induced Fanconi's syndrome associated with adefovir dipivoxil treatment for hepatitis B. Intern Med 53: 233-237, 2014.

The Internal Medicine is an Open Access journal distributed under the Creative Commons Attribution-NonCommercial-NoDerivatives 4.0 International License. To view the details of this license, please visit (https://creativecommons.org/licenses/ by-nc-nd/4.0/).

\footnotetext{
${ }^{1}$ Department of Nephrology, Rheumatology, Endocrinology and Metabolism, Okayama University Graduate School of Medicine, Dentistry and Pharmaceutical Sciences, Japan, ${ }^{2}$ Department of Nephrology, Keiyu Hospital, Japan and ${ }^{3}$ Department of Chronic Kidney Disease and Cardiovascular Disease, Okayama University Graduate School of Medicine, Dentistry and Pharmaceutical Sciences, Japan Received: October 3, 2018; Accepted: November 4, 2018; Advance Publication by J-STAGE: February 1, 2019 Correspondence to Dr. Haruhito A. Uchida, hauchida@okayama-u.ac.jp

(C) 2019 The Japanese Society of Internal Medicine. Intern Med 58: 1659, 2019
} 